\section{Brain death in Japan}

SIR - Last December, new criteria for the diagnosis in Japan of "brain death" were announced by an advisory panel of the Ministry of Health and Welfare (see Nature 318, 591; 1985). I would like to make some further comment and discuss the controversy that has arisen over a transplant operation carried out at Tsukuba. I have been involved in the Patients Rights Conference (PRC) in Tokyo University Hospital for several years. PRC has discussed many cases of medical malpractice and experiments on humans brought to its notice by the victims or their relatives.

The main topic of discussion at present in PRC is brain death. PRC has now held six symposia at Tokyo University to try to understand what brain death really means and those invited have included transplant surgeons, neurosurgeons, neuropsychiatrists, anaesthetists, pediatricians, nurses, lawyers, writers, Diet members, victims of medical malpractice and the handicapped. Recently, we have focused on the case of the first combined pancreas and kidney transplantation (see Nature 313, 613; 1985).

According to newspapers and doctors at Tsukuba University, the donor was a neuropsychiatric female patient diagnosed as brain dead after severe brain haemorrhage. The donor had been suffering from psychiatric symptoms derived from cerebrovascular disease and admitted to a local psychiatric hospital. When she went into deep coma, and her husband was told her spontaneous breathing would soon stop, he proposed that doctors should make use of her organs for transplantation, as she had wished.

Immediately after spontaneous respiration stopped, the transplant team began preparations, while the neurosurgeon abandoned treatment before the definite diagnosis of brain death. At first, the team planned to perform a liver transplant but could not find an appropriate recipient. Finally it was decided to perform a combined pancreas and kidney transplant. This quick change raised ethical questions of whether well-informed consent could be obtained from the recipient. The result of the operation was far from satisfactory; the patient died in less than a year from intra-abdominal bleeding from the resected part of the transplanted pancreas. The 29-year-old patient's case (diabetic nephropathy) was presented at the meeting of the Japan Transplant Association last year, at which questions were asked about the adequacy of the diagnosis of brain death, indication of transplant, operation technique and post-operative care. Unfortunately, satisfactory answers were not received from Dr Iwasaki and his colleagues. I should further mention that Dr Iwasaki has written no articles on pancreas transplantion in his twenty-year career and may have insufficient experience for this procedure.

PRC sees the following problems in the operation: (1) the possibility that necessary treatment for the basic disease of the donor was abandoned; (2) transplant from a brain-dead patient before the establishment of the criteria of brain death; (3) discrimination against the psycho-handicapped whose medical-legal competence was questionable, and the validity of the consent obtained from the guardian; (4) the adequacy of the selection of the recipient who could have survived longer if treated conventionally, with insulin and haemodialysis, for example.

PRC asked Dr Iwasaki for a meeting to discuss the case. Unfortunately he refused, so PRC felt obliged to file the lawsuit against him and his colleagues described in Nature in order to have a chance to discuss the matter openly in public.

Faculty of Medicine,

KaTSUNORI HONDA

University of Tokyo,

7-3-1, Hongo, Bunkyo-ku, Tokyo, Japan

\section{Embryo research}

SIR-David Davies's letter (Nature 320, 208; 1986) makes me more than ever aware that, as the only embryologist on the Warnock Committee of Inquiry into Human Fertilization and Embryology, I was wrong in not insisting on a logical and unambiguous terminology. I missed the first meeting, at which it was decided to apply the term "embryo" to all stages from fertilization onwards, but that is no excuse: plenty of other decisions were changed during the 20 months that the committee sat.

Traditionally, the embryo is the entity that is formed only at the primitive streak stage, the entity which then develops into the fetus and ultimately into the baby. In recent years, embryologists (including me) have adopted the sloppy practice of using the same term for the entire product of the fertilized egg, most of which differentiates before the formation of the primitive streak into tissues that will protect and nourish the future embryo. The ambiguity is well illustrated (unintentionally) in an excellent recent paper describing experimental studies on early marsupial development (Selwood, L., J. Embryol. exp. Morphol. 92, 71; 1986). The author refers to "2-cell embryos", "4-cell embryos, "14to 16-cell embryos", "one embryo, which was a complete blastocyst with about 22 cells"; she then states: "The cells that will later give rise to the embryo [my italics] are at this stage indistinguishable from the rest of the blastocyst". The embryologist knows what is meant; the uninitiated must be left gasping.

David Davies writes: “... we were all well aware that the human embryo for the first two weeks of its existence... bears no visual resemblance whatever to the later embryonic and fetal stages". This misses the point. As defined above, the embryo does not exist for the first two weeks after fertilization. It is formed from a tiny subset of the mass of cells generated during that period by the fertilized egg. Alternative terms for this mass of cells, and any earlier stage back to the fertilized egg, include conceptus, zygote, pre-embryo and pro-embryo ("an embryonic structure preceding true embryo", Henderson's Dictionary of Biological Terms, 9th edn April 1985). All avoid the confusing ambiguity of "embryo".

"Cosmetic words", says Dr Davies. Cosmetics hide, clarity illuminates. I strive for clarity, and regret that I have not done so more effectively in the past.

ANNE MCLAREN

MRC Mammalian Development Unit,

Wolfson House, 4 Stephenson Way,

London NW1 $2 \mathrm{HE}, \mathrm{UK}$

\section{Justifiable risks}

Sir-Your leading article "Why did Challenger matter?" (Nature 319, 435; 1986) again shows the difficulty of defining "essential". It says "Last week's tragedy shows... there is now no case for carrying on shuttle flights passengers whose presence is not essential. There should be no more schoolteachers, congressmen or even journalists until experience has shown shuttle flights to be mere routine."

If our ancestors had taken that view, most of us over here would still be over there in Europe with you rather than here where the opportunities as well as the risks are more abundant!

University of Alabama

James A. Pittman $J_{R}$

School of Medicine,

University Station,

Birmingham, Alabama 35294, USA

\section{More ways than one}

SIR-While scientists in Oxford are planning to use genetically engineered viruses to kill the caterpillars of Panolis flammea which infect pine trees ${ }^{1}$, Chinese scientists in Anhui Province are employing trained grey magpies to eat up pine moths and larvae ${ }^{2}$, a method that seems to be efficient and versatile. Each bird catches about 18,000 pine moths a year and these birds can be moved to another infected area when the moths in one tract are largely exterminated.

Pang-Chui Shaw

Biotechnology Centre,

Imperial College of Science

and Technology,

London SW7 2AZ, UK

Newmark, P. Nature 320, 2 (1986).

2. China Pictorial No. 2, $42-43$ (1986) 